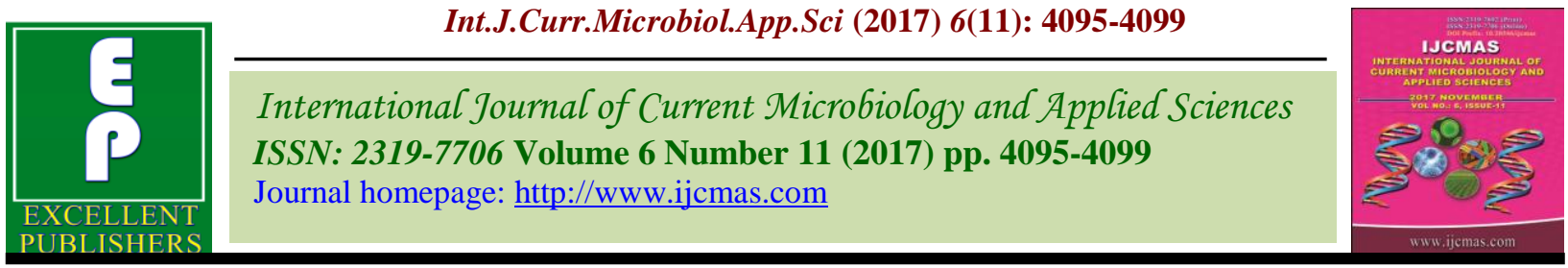

Case Study

https://doi.org/10.20546/ijcmas.2017.611.479

\title{
Successful Management of Hydroallantoisin A Non-Descriptive Goat
}

\author{
S. Alagar*, C. Velladurai, S. Manivannan and M. Selvaraju \\ Department of Veterinary Gynaecology and Obstetrics, India \\ *Corresponding author
}

\section{A B S T R A C T}

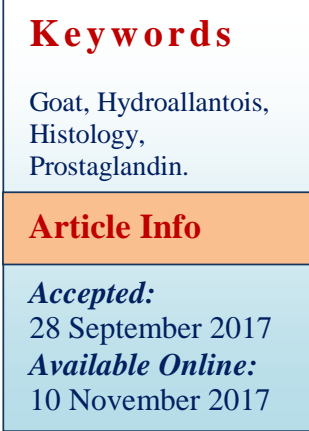

A case of hydroallantois and its clinical management in a full term pregnant 3 kidding pleuriparous non-descriptive goat having symptoms of anorexia, respiratory distress, bilateral abdominal distension, reluctant to move and stand was reported. Abdominal palpationwas revealed enlarged uterus with presence of large volume of fluid. Fluid therapy along with prostaglandin (cloprostenol sodium) and dexamethasone was administered for induction of parturition and managing the shock. One non-viable fetus was delivered by gentle traction. Average allantoic fluid 7-10 liters was removed. Parenteral (day 5) as well as intra-uterine antibiotic (2 days) coverage was given. Placentas were expelled out after 24 hours.

\section{Introduction}

Hydroallantois, a placental dropsical condition characterized by progressive bilateral abdominal distension, respiratory distress, depression, tendency to adopt recumbent posture, difficulty in standing and walking is caused by abnormal accumulation of large volume of allantoic fluid in the uterus of pregnant female during 5-20 days period in last trimester of pregnancy.

It has been commonly reported to occur in bovine, Bubaline, equine and rarely in ovine, canine and caprine (Milton et al., 1989; Kumar et al., 2012 and Feliciano et al., 2013).

A reduction in the number of cotyledons has also been associated with hydrallantois (Peek, 1997). Decreased active transport of sodium across the chorioallantoic membrane, increased permeability of the chorioallantoic membrane, hormonal imbalances, fetal renal disease (Morin et al., 1994), multiple fetuses in the uterus, fetal liver disease, uterine torsion and/or twisting of the umbilical cord, deficiency of vitamin A causing decreased endometrial resistance to infections (compromises the number of caruncles)

Malnutrition conditions and heart or renal diseases of the ewe (Toniolloand Vicente, 1993) may contribute to this process.

Present paper reports about a rare case of Hydroallantois and its successful therapeuticobstetrical management in a non-descriptive goat. 


\section{Case history and clinical observation}

A 4-year-old non-descriptive doe was presented with history of full term pregnant and sudden bilateral distention of abdomen (Fig. 1), anorexia, respiratory distress, expiratory grunt, difficulty in getting up. The animal was dull and depressed with sunken eye balls. The physiological parameters such as pulse rate, respiratory rate and rectal temperature were within physiological limit. Vaginal examination revealed patent vaginal passage, absence of vaginal discharge and intact cervical seal. Based on history, symptoms and observations, this case was diagnosed as hydrallantois.

\section{Treatment}

Due to the proximity of the parturition and the clinical conditions of the patient, it was decided to induction of parturition. The goat was treated with prostaglandin $1 \mathrm{ml}(250 \mu \mathrm{g})$. 36 hours after induction parturition cervix was three finger dilation, cervix was fully dilate after fanning and feathering along with $50 \mathrm{ml}$ of calcium diluted with $150 \mathrm{ml}$ of normal saline. To avoid shock due to sudden release of allantoic fluid, rusch catheter (18") was introduced into the allantoic cavity through cervix. Simultaneously intravenous fluid (normal saline $500 \mathrm{ml}$ ) was given.

After removal of excessive Allaonticfluids, Presentation (P1) anterior longitudinal, Position (P2) - right dorso-ilial, Posture (P3) bilateral shoulder flexion. The dead nonviable, immature normal male fetus was delivered by simple traction. The diseased placenta was removed manually. Following fetal delivery inj. Calcium borogluconate (150 $\mathrm{ml}, \mathrm{i} / \mathrm{v})$ and inj. Oxytocin (20 IU, i/v) were administered. The animal was treated with inj. Enrofloxacin (250mg, i/m), inj. Meloxicam (25 $\mathrm{mg}, \mathrm{i} / \mathrm{m})$, inj. DNS (250 $\mathrm{ml}, \mathrm{i} / \mathrm{v})$, inj. Ringer lactate $(150 \mathrm{ml}, \mathrm{i} / \mathrm{v})$ and inj.
Chlorpheniramine maleate, $2 \mathrm{ml} \mathrm{i} / \mathrm{m}$. The antibiotic, antihistamine and fluids were continued for one week and dam recovered uneventfully.

\section{Results and Discussion}

Hydrallantois is the single pathologic factor present in 85 to 90 per cent of dropsical conditions in the bovine (Toniollo et al., 2003). Normal allantoic fluid volume in sheep and goats has been reported to be between 0.5 to 1.5 liters (Mary and David, 2009). 6 to 18 liters of amniotic fluid has been reported to remove from the cases of hydroallantois in sheep and doe (Philip et al., 2012). In present case, 7-10 liters of allantoic fluid was removed per vaginal. The exact cause of hydrallantois is not certain but it has been reported to associated with consumption of legumes with high estrogens, hypothyroidism and placental or uterine disease (Mobini et al., 2002) or diseased uterus wherein caruncles are not functional and rests of the placentomes are enlarged and diseased (Bhattacharyya et al., 2012) or development of adventitial placentation (Misri, 2001). The abnormal functioning of placentomes has been attributed to inadequate numbers of caruncles (Misri, 2001). The deficient numbers of caruncles associated with hydroallantois may be due to either a congenital lack of development or uterine disease acquired in later life (Peek, 1997).

The cause of hydrallantois in this ewe was notcertain. Since no abnormalities were detected in the fetuses and placental edema was the only lesion found, we believe that this could have caused a decrease in the active transport of sodium across the chorioallantoic membrane or an increase in the permeability of the chorioallantoic membrane (Peiró et al., 2007). Hormonal imbalances due to phytoestrogens ingestion (Adams et al., 1981) in the pasture cannot be discarded. 

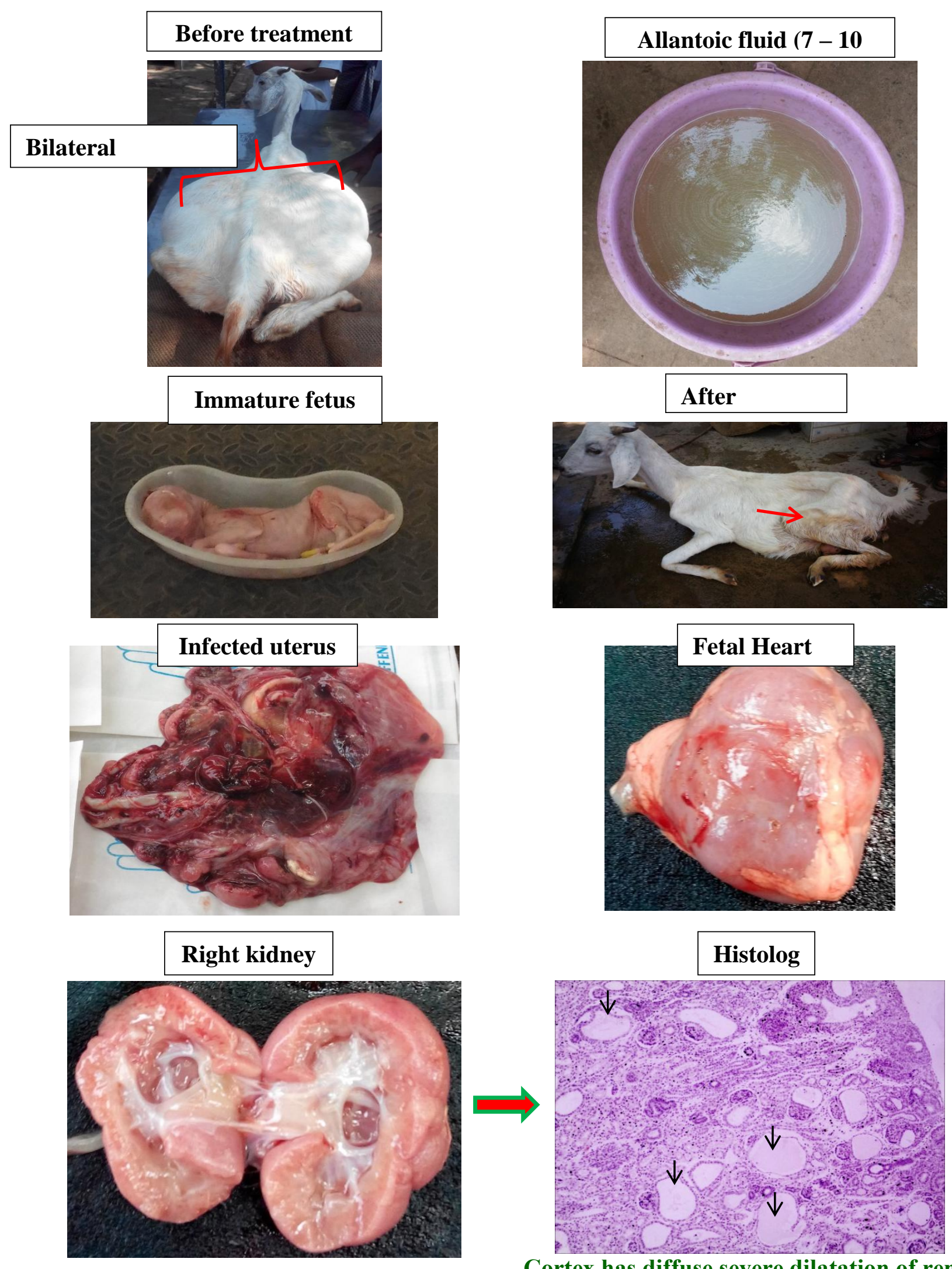

Cortex has diffuse severe dilatation of renal tubules. 

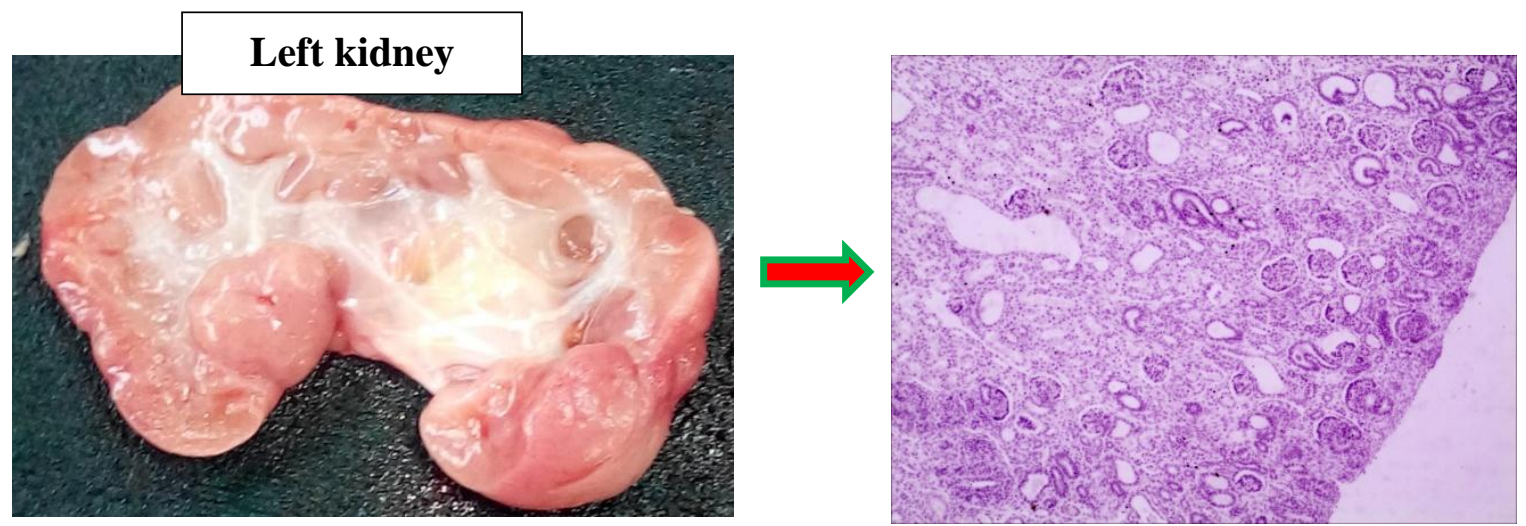

Cortex showed diffuse moderate dilatation
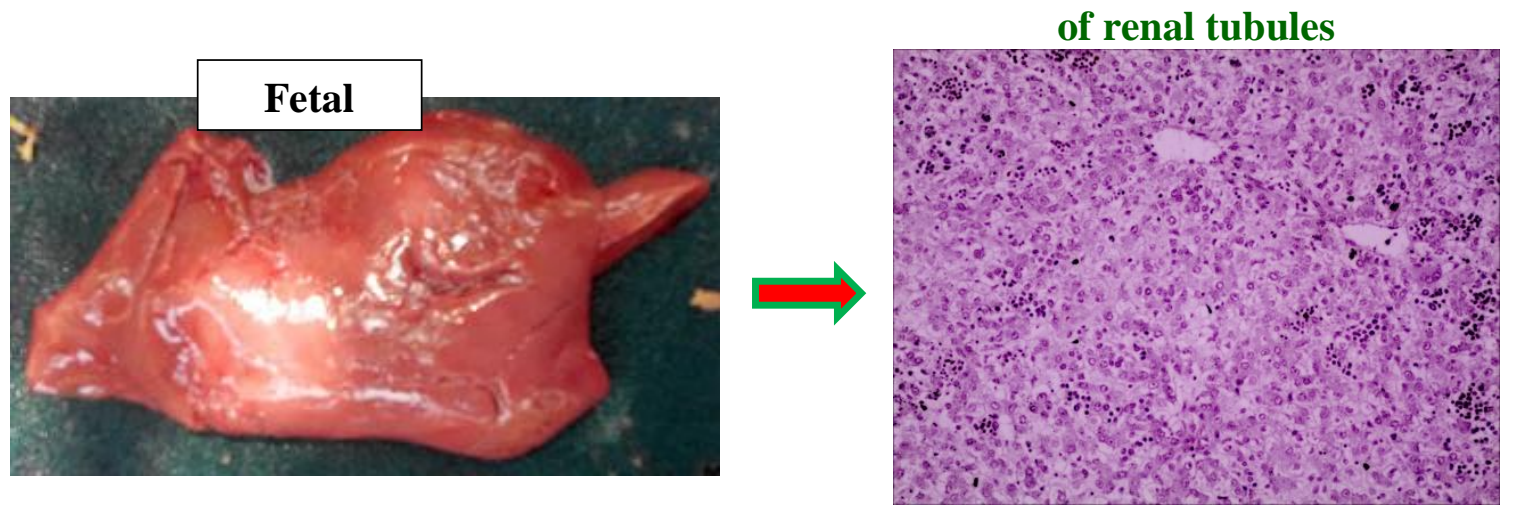

Normal haemopoietic liver

Bhattacharyya et al., (2012) and Morin et al., (1994) preferred caesarian section for relieving severe abdominal discomfort and respiratory distress. In present case prevaginal relieving of allontoic fluid is carried out. Most fetuses of animals with hydrallantois are under developed with congenital defects or are apparently normal but not viable (Morin et. al., 1994) in present case one non-viable and underdeveloped fetus was observed.

\section{References}

Adams, N. R., H. Hearnshaw and C. M.Oldham, 1981.Abnormal function of the corpus luteum in some ewes with phyto-estrogenic infertility. Australian Journal of Biological Science.34: 61-65.

Bhattacharyya, H.A., S. H. Dar, M. R. Fazili and A. Hafiz, 2012. A Typical Case of Hydrallanto is accompanied by Fetal

Monstrosity in a Local Ewe of Kashmir. Veterinary Research Forum.3: 221 223.

Feliciano, M. A. R., D. J. Cardilli, R. M. Crivelaro, E. Garrido, M. A. M. Silva, T.L.L. Castanheira and W.R.R Vicente,2013. Hydrallantois in a female dog: a case report. Arquivo Brasileiro de Medicina Veterinária e Zootecnia, 65: 1091-1095.

Kumar, S., U. Sharma, A. K. Pandey, S. Agarwal, R. B. Kushwaha and A. K. Tripathi, 2012. Hydroallantois in Buffalo: A Case Report. Buffalo Bulletin.31: 67-69.

Mary C. Simth and David and M. Sherman, 2009.Periparturient Problems; Hydrops of Uterus; in Goat Medicine, $2^{\text {nd }}$ edition., Wiley-Blackwell, Lowa, USA.

Milton, A., B.Welker and P. Modransky, 1989. Hydrallantois in Ewe. J. Am. Vet. Med. Assoc., 195:1385-86. 
Misri, J., 2001. Hydrallantois in a goat. Indian Veterinary Journal, v.78, p.255-256, 2001.

Mobini, S., A. M. Health and D. G. Pugh, 2002.Theriogenology of sheep snd goats. In: Sheep and Goat Medicine. Ed: Pugh, D.G W-B Saunders co. Philadelphia. 129-186.

Morin, D. E., L. Hornbuckle, L. Rowan and H. E. Whiteley 1994.Hydrallantois in a caprine doe. J. Am. Vet. Med. Assoc., 204:108-111.

Morin, D. E., T. Hornbuckle, L. L. Rowan and H. E. Whiteley, 1994.Hydrallantois in a caprine doe. Journal of American Veterinary

Medical Association, 204:108-111.

Peek, S. F. 1997. Dropsical conditions affecting pregnancy. In: Youngquist, R. S. Current Therapy in Large Animal
Theriogenology. $1^{\text {ed }}$., W. B. Saunders, 400-403.

Peiró, J. R., A. S. Borges, R. Yanaka, M. B. Koivisto, L. C. N. Mendes, F. L. F. Feitosa, J. O. Abujamra, C. A. Rodrigues, 2007. Hydrallantois in ewe (Case Report). ArsVeterinaria, Jaboticabal, 23:116-119.

Philip, L. M., M. R. Mohan and P. F. Bastin, 2012. Fetal Anasarca Twins with Hydroallantois in Malabari Does. J. Ind. Vet. Assoc., Kerala.10: 52-53.

Toniollo, G. H. and W. R. R. Vicente, 1993.Manual de Obstetrícia Veterinária. $1^{\text {ed }}$, São Paulo, Livraria Varela.

Toniollo, G. H., W. R. R. Vicente and M. B. Carvalho, 2003.Manual de Obstetrícia Veterinária. 1edn., São Paulo, Livraria Varela.

\section{How to cite this article:}

Alagar, S., C. Velladurai, S. Manivannan and Selvaraju, M. 2017. Successful Management of Hydroallantoisin A Non-Descriptive Goat. Int.J.Curr.Microbiol.App.Sci. 6(11): 4095-4099. doi: https://doi.org/10.20546/ijcmas.2017.611.479 